NBER WORKING PAPERS SERIES

\title{
A THEORY OF PERSISTENT INCOME INEQUALITY
}

Steven N. Durlauf

Working Paper No. 4056

\author{
NATIONAL BUREAU OF ECONOMIC RESEARCH \\ 1050 Massachusetts Avenue \\ Cambridge, MA 02138 \\ April 1992
}

Much of this paper was written during a visit to the London School of Economics, whose hospitality I gratefully acknowledge. I thank Kenneth Arrow, Russell Cooper, Suzanne Cooper, Hugo Hopenhayn, Paul Johnson, Mordecai Kurz, Glenn Loury, Susan Nelson, Uday Rajan, David Starrett, Jeroen Swinkels as well as seminar participants at Boston University, Cambridge University, Dartmouth, FRB Minneapolis, MIT, NBER Working Group on Macroeconomic Complementarities, Oregon, Rochester, Southern California, Stanford and Western Ontario for many helpful comments. The Center for Economic Policy Research has generously provided financial support. This paper is part of NBER's research programs in Growth and Economic Fluctuations. Any opinions expressed are those of the author and not those of the National Bureau of Economic Research. 
NBER Working Paper \#4056

April 1992

\title{
A THEORY OF PERSISTENT INCOME INEQUALITY
}

\begin{abstract}
This paper explores the dynamics of income inequality by studying the evolution of human capital investment and neighborhood choice for a population of families. Parents affect the conditional probability distribution of their children's income through the choice of a neighborhood in which to live. Neighborhood location affects children through two mechanisms. First, the level of education depends on the total income of a neighborhood, as all school funding is determined by majority voting. Human capital markets are incomplete as neighborhoods cannot borrow to supplement tax revenues available for education. Second, the conditional probability distribution of individual-specific productivity shocks is affected by the income distribution within a neighborhood. This dependence reflects cultural influences such as the presence in a community of successful role models. These forces interact to endogenously stratify the economy as families segregate themselves into economically homogeneous neighborhoods. Our model has two important features. First, starting from identical initial conditions, families can exhibit different long term income levels, leading to persistent income inequality. Second, areas of permanent poverty can emerge endogenously in a growing economy as neighborhood-wide feedback effects transmit poverty across generations.
\end{abstract}

\author{
Steven N. Durlauf \\ Department of Economics \\ Stanford University \\ Stanford, CA $9.4305-6072$ \\ and NBER
}




\section{Introduction}

Starting with Becker and Tomes [1979] and Loury [1981], many researchers have examined models explaining a nondegenerate cross-section income distribution. (See Galor and Zeira [1989], Banerjee and Newman [1991], Aghion and Bolton [1991] and Bénabou [1991] for some important recent contributions.) In both the Becker-Tomes and Loury formulations, a central role is played by the evolution of families across time where parents affect children's income earnings potential through human capital investment. Generally, researchers have assumed that human capital markets are incomplete in the sense that human capital formation cannot be financed by issuing claims against a child's future earnings due to the lack of enforceability of such contracts. Human capital investment is thus constrained by the level of parental income. As a result, high income families are better able than poor families to invest in human capital and income disparities are passed on across generations. Consequently, imperfect human capital markets can induce substantial serial correlation in the time series profile of income distribution as relative income rankings change slowly over time.

Despite the ability of these models to explain some stickiness in relative income rankings, this work has centered on models with a striking implication for the average behavior of families over time. With the exceptions of Galor and Zeira [1989] and Bénabou [1991], these models generally predict that average incomes are equal for all families, when computed over sufficiently long time horizons. Further, the models imply that there is no asymptotic tendency for one family to rank above another in income. Becker and Tomes [1979] in fact argue that these features are reflected in the data since cross-section regressions of child income on parental income typically imply relatively rapid mean reversion in family income. (Solon [1990], however, provides evidence that these studies underestimated the impact of parental income on children's income.)

Granting that the cross-section income distribution exhibits mean reversion, there also exists substantial evidence of persistence in the tails of the income distribution. 
In sociology, many scholars have argued in favor of the existence of an "underclass" of chronically poor people who are trapped in ghettos and are victims of a "culture of poverty". Wilson [1987] has documented the growth and persistence of the chronically poor in a number of studies. Wilson's work has emphasized the idea that as middle- and upper-class blacks have moved outside of historically segregated neighborhoods, the remaining residents have found themselves confronted by a breakdown of social and economic institutions which has rendered poverty in these neighborhoods selfperpetuating. This breakdown has been attributed to economic factors such as the lack of an adequate tax base to support schools, as well as sociological explanations such as the lack of successful role models to motivate children to try to leave the ghetto. Streufert [1991] formally models this phenomenon and shows how the absence of successful role models can inhibit the ability of the young to correctly infer the benefits of high education investment. These ideas are consistent with the empirical findings of Datcher [1982] and Corcoran, Gordon, Laren and Solon [1989] that neighborhood characteristics are an important determinant of individual income levels. Even those studies such as Jaynes and Williams [1989] which reject the idea of a culture of poverty accept the view that poverty may be self-perpetuating when low community income leads to low human capital formation.

Many studies exist which document substantial persistence in relative income rankings. A major analysis is due to Brittain [1977], who explored relative income in the US. Brittain examined the correlations between measures of overall economic status for fathers and sons based upon a survey of 659 fathers who died in Cleveland in 1964-1965. ${ }^{1}$ Brittain's analysis found that parental economic status played a significant role in determining the economic status of sons. For example, among fathers whose relative

\footnotetext{
${ }^{1}$ The overall index of the economic status of fathers is based upon a weighted average of variables which measure education, race, occupation type, family size, religion and wealth, whereas the index of overall status of sons is computed as a weighted average of variables measuring family income, occupation type and quality of residence. This index thus represents a proxy for permanent income. See Brittain [1977] for details.
} 
status ranking was in the top $10 \%$ of the sample, the average son's percentile ranking was $13 \%$. Conversely, for fathers whose percentile ranking was $90 \%$ or below, the average son's percentile ranking was $71.8 \%$.

Similar evidence exists for intragenerational persistence. Bane and Ellwood [1986] have shown how the chronic or long term poor are a major component of total poverty in the United States. Using the Panel Study of Income Dynamics, these authors have decomposed the current poor population by length of spell in poverty. Bane and Ellwood demonstrate that although most people who are ever poor experience only brief spells of poverty, a large percentage of total poverty is associated with chronic spells. Over $50 \%$ of the poor at a fixed point in time are experiencing spells which last over 8 years, the length of their available sample, whereas only $25 \%$ are experiencing spells of less than 4 years, illustrating the magnitude of long term poverty. Similar results for a longer data set are reported by Adams, Duncan and Rogers [1988]. Studies such as these, when combined with the more field-oriented work in sociology, strongly support the view that there is substantial intertemporal and intergenerational persistence in economic status, especially at the lower extreme of the income distribution.

One important implication of the work on the underclass is that a family's income is not a sufficient statistic for determining whether poverty persists across generations. Community-wide forces determine a child's economic prospects. These feedbacks are not necessarily attitudinal. For example, if education is a public good, then community rather than family income determines human capital formation. The complex ways in which community-level forces determine individual income is reflected in the contrast between the relatively transitory poverty of various immigrant groups arriving in the early 20 th century, versus the conclusions drawn about contemporary inner-city poverty.

This paper attempts to understand persistent income inequality by constructing a dynamic model of income distribution. Following Loury and Becker and Tomes, we model intragenerational persistence through the impact of human capital formation on 
earnings. Agents in our economy are poor because of lack of skills. This assumption ensures that poverty persists throughout adulthood. To understand intertemporal persistence, we focus on the role of community income in human capital formation. ${ }^{2}$ We extend the work of previous authors in two directions. First, we model education as a local public good, allowing different communities to choose different levels of human capital investment. As a result, average income in a community is a primary determinant of human capital investment per child. ${ }^{3}$ We also allow the distribution of productivity shocks to be influenced by neighborhood composition. These factors allow high and low incomes to be self-reinforcing within neighborhoods. Second, each family chooses a neighborhood in which to live, subject to income requirements. The rich can therefore choose to isolate themselves from the poor. Collectively, these features induce a complex pattern of income dynamics which can lead to persistent income inequality. ${ }^{4}$

By modelling individual education levels and productivity as functions of neighborhood behavior, we introduce a mechanism by which each family's opportunity set is affected by the choices of others. This idea has been the basis for much recent work

${ }^{2}$ Our emphasis on human capital as a fundamental determinant of economic status is consistent with a large body of empirical evidence. Johnson and Stafford [1973], Wachtel [1976], Card and Krueger [1990] all find that improvements in educational quality, measured along different dimensions including per pupil expenditure, significantly improve future earnings.

${ }^{3}$ See Kozol [1991] for a description of how the lack of adequate funding has affected education quality in poor school districts throughout the US. Kozol documents how per capita student expenditure differences on the order of $75 \%$ to $100 \%$ between adjacent inner city and suburban schools are not uncommon, with the New York City and Chicago areas representing two prominent examples.

${ }^{4}$ Galor and Zeira [1989] show how if the poor cannot borrow at low enough interest rates, then multiple long run equilibria can exist in family income. Our model, however, explains how initially identical families can diverge, leading to complex dynamics as families move in and out of poverty and has very different predictions about which variables determine whether a family becomes trapped in poverty. Schelling [1971] derives complementary results to ours in the context of racial segregation by using mechanical rules for neighborhood formation. 
in economic theory and underlies a number of models of multiple equilibria (see Cooper and John [1988] or Durlauf [1991] for examples in macroeconomics). One important distinction between our model and previous work is that we do not rely on positive feedbacks between agents to generate multiplicity in long run behavior. (Our model exhibits negative feedbacks across some agents.) Instead, our analysis relies on the feature of "endogenous stratification" of the economy - which we define as the tendency in the economy for agents of similar characteristics to choose to interact with one another. Endogenous stratification leads the rich to segregate themselves from the poor in our model, which can produce distinct neighborhoods with different long run characteristics.

Methodologically, we extend an approach developed in Durlauf [1991] which requires us to compute an equilibrium stochastic process describing the evolution of each family as the population endogenously sorts itself into neighborhoods. We exploit the properties of the stochastic process to describe the long run dynamics of the economy. When the long run behavior of families with identical initial conditions diverges, then the economy exhibits permanent income inequality. In this case, the stochastic process characterizing the aggregate economy is nonergodic.

Our analysis also provides a way of understanding how agents evolve towards different equilibria. The many papers in the coordination failure/multiple equilibrium literature (see Cooper and John [1988] for an overview) have generally concentrated on demonstrating the existence of multiple steady states in an economy, without explaining how different equilibria actually come about. Further, this literature generally assumes that all agents end up at the same equilibrium. Our results indicate how endogenous stratification models can allow distinct long run equilibria to emerge among groups of agents as a consequence of the particular sample path realization of the economy. ${ }^{5}$

${ }^{5}$ Our model can exhibit multiple long run equilibria for individual families in the sense that the long run average behavior of each family's income depends on the sample path realization of the economy. Some sample paths lead a family to persistent poverty whereas others do not. 
Two basic conclusions emerge from the analysis. First, we show that if endogenous stratification and within-neighborhood feedback effects are strong enough, arbitrarily persistent income inequality can occur between families with identical initial conditions. Second, we show that neighborhoods where no one escapes poverty can emerge and coexist with wealthy communities even in an economy experiencing economic growth. These features hold due to the economic segregation of families through neighborhood formation. Our results indicate how community factors must be accounted for in determining whether a family is trapped in poverty.

Section 2 of the paper describes the evolution of family income. Section 3 characterizes the equilibrium income distribution when all human capital investment is private. Section 4 analyzes the aggregate equilibrium when human capital is an economy-wide public good. Section 5 characterizes the behavior of the economy with endogenous neighborhood formation and local public goods. Some sufficient conditions are provided for persistent inequality to emerge in an economy. Section 6 considers a variant of the model which addresses the issue of the breakup of urban centers and the emergence of inner city poverty. Section 7 contains a summary and conclusions. A Technical Appendix is available from the author which contains proofs for all theorems.

\section{A model of evolving families}

We first outline a model of human capital formation and income determination for a population of overlapping generations.

\section{i. Population structure}

The population consists of a finite collection of families, indexed by $i$. The collection of all families is denoted as $\mathfrak{\Im}$; the total number of families is fixed at some 
finite number $I$. Each generation within a family lives two periods. We shall refer to the person born in family $i$ at $t-1$ as agent $i, t-1$; family $i, t$ is composed of agent $i, t-1$ and his offspring. In the first period, the young receive education or human capital investment which acts to affect their earnings potential when old. In the second period, each old person works, has one child and makes a decision as to how much to consume and how much human capital he would like to see invested in his offspring. Human capital investment is a public good; its determination is discussed below.

Families are organized into distinct neighborhoods. We denote the physical location of a neighborhood as $d$ and the collection of families occupying location $d$ at $t$ as $\mathfrak{N}_{d, t}$. The number of neighborhoods is assumed to be at least as large as the number of families; not all neighborhoods need to be occupied each period. Membership is exclusive; family $i, t$ cannot belong to more than one neighborhood. Neighborhoods may vary according to size, so we define $\#\left(\mathfrak{N}_{d, t}\right)$ as the number of families in neighborhood $d$ at $t$. Taxes and human capital investment are determined at the neighborhood level.

\section{ii. Preferences}

Agent $i, t-1$ maximizes the expected utility function

$$
E\left(u\left(C_{i, t}\right)+v\left(Y_{i, t+1}\right) \mid \mathfrak{F}_{t}\right),
$$

where $C_{i, t}=$ consumption of $i, t-1$ when old, $Y_{i, t+1}=$ income of offspring $i, t$ when old and $\mathfrak{F}_{t}$ denotes all information available at $t$. The functions $u(\cdot)$ and $v(\cdot)$ are continuous and nonconvex with the restrictions

$$
u(\infty)=v(\infty)=\infty ; \quad \frac{d u(\infty)}{d C_{i, t}}=\frac{d v(\infty)}{d Y_{i, t+1}}=0
$$

Finally, we assume that there is no disutility of work so that each agent applies his full 
labor endowment $\bar{L}$ to the highest paying job for which he is qualified.

\section{iii. Production technology}

Aggregate output $Y_{t}$ is produced by a standard neoclassical production function which takes as arguments different occupations $L_{1, t} \ldots L_{K, t}$. The number of occupations will in some contexts be assumed to equal infinity. ${ }^{6}$ The aggregate production function is linear in the labor types,

$$
Y_{t}=\sum_{k=1}^{K} w_{k} L_{k, t}
$$

ensuring that labor type $k$ has constant marginal product $w_{k}$. All occupations are paid their marginal product; the sequence $\bar{Y}_{1}=w_{1} \bar{L}, \bar{Y}_{2}=w_{2} \bar{L}, \ldots$ defines the state space for family $i, t$ 's income. We assume that $\bar{Y}_{k+1}-\bar{Y}_{k}$ equals 1 for all $i$. We therefore denote the joint state space for all family incomes as $\bar{Y}^{I}$, the space of $I$-length vectors of positive integers. $Y_{i}=\left\{Y_{1, t}, \ldots Y_{I, t}\right\}$ represents a realization in this state space. Poverty occurs when a parent's income is less than or equal to $\bar{Y}^{\text {pov }}$, the income associated with the $p^{\prime}$ th occupation. At time -1 , all families are assumed to have identical initial incomes above the poverty line, i.e. $Y_{i,-1}=Y_{j,-1}>\bar{Y}^{\text {pou }} \forall i, j$ and to be located in equal size neighborhoods.

\section{iv. Education constraints on labor supply}

Each agent is constrained in the type of labor he can supply by the amount of human capital invested in him. $H_{i, t}=$ human capital invested in agent $i, \imath$ during youth.

${ }^{6}$ It is perhaps more natural to assume that $K$ is an increasing function of time and becomes asymptotically infinite. In this case, technical change manifests itself as the emergence of more and more productive occupations over time. Such an alternate formulation would have no effect on our results. 
The level of human capital invested in the young, places an upper bound on the set of occupations which can be entered when old. Letting $\theta_{i, t}=r$ if occupation $r$ is chosen by agent $i, t-1$, then

$$
\exists \text { numbers } e_{1} \ldots e_{K} \text { such that if } e_{k} \leq H_{i, t-1}<e_{k+1} \text { then } \theta_{i, t} \leq \max \left(1, k+\zeta_{i, t}\right) \text {. }
$$

$\zeta_{i, t}$ is a human capital productivity shock. The support of $\zeta_{i, t}$ is uniformly bounded. The max operator accounts for the existence of a lowest paying occupation.

\section{v. Relationship between human capital and productivity increases}

We impose a non-increasing returns condition on the implied relationship between human capital formation and productivity.

$$
\frac{\bar{Y}_{m+1}-\bar{Y}_{m}}{e_{m+1}-e_{m}} \text { is nonincreasing in } m \text {. }
$$

However, we do assume that the marginal benefit of additional skill acquisition relative to the cost of human capital formation does not become asymptotically negligible. Specifically, we assume that there exists a $c>0$ such that

$$
\frac{\bar{Y}_{m+1}-\bar{Y}_{m}}{e_{m+1}-e_{m}}>c \forall m
$$

This technology allows the implicit production function converting human capital into output to become asymptotically linear, as in Jones and Manuelli [1990].

\section{vi. Budget constraint}

Agent $i, t-1$ divides income between consumption $C_{i, t}$ and taxes $T_{i, t}$. 


$$
Y_{i, t}=C_{i, t}+T_{i, t}
$$

\section{vii. Human capital formation}

The level of human capital is determined by the total taxes collected and number of children in a neighborhood. Given the desired level of per capita human capital and the number of families in a neighborhood, the function $g\left(H_{i, t}, \#\left(\mathfrak{N}_{d, t}\right)\right)$ determines the required level of per capita neighborhood human capital expenditure. We assume that necessary per capita expenditures increase in the desired level of education,

$$
\frac{\partial g\left(H_{i, t} \#\left(\mathfrak{N}_{d, t}\right)\right)}{\partial H_{i, t}}>0
$$

and that the function is not concave,

$$
\frac{\partial^{2} g\left(H_{i, t} \#\left(\mathfrak{\Re}_{d, t}\right)\right)}{\partial{H_{i, t}}^{2}} \geq 0
$$

Finally, we assume that per capita expenditures is decreasing for a fixed human capital level, which creates a possible incentive for large neighborhoods.

$$
\frac{\partial g\left(H_{i, t} \#\left(\mathfrak{N}_{\boldsymbol{d}, t}\right)\right)}{\partial \#\left(\mathfrak{N}_{\boldsymbol{d}, t}\right)}<0
$$

viii. Structure of taxes

All taxes are proportional to income. Tax rates $\tau_{d, t}$ are set at the neighborhood level each period.

$$
T_{i, t}=\tau_{d, t} Y_{i, t} \text { where } i \in \mathfrak{N}_{d, t}
$$




\section{ix. Determination of tax rate}

$\tau_{d, t} \in[0,1]$ is an equilibrium tax rate for families in $\mathfrak{R}_{d, t}$ if at least one half of the members of neighborhood $d$ prefer the rate to any given alternative. A neighborhood's tax rate is always chosen after income is determined for all its members. Any nonuniqueness in equilibrium tax rates is resolved, without loss of generality, by choosing the highest tax rate among the candidates for an equilibrium rate. We similarly assume that if a family is indifferent between two neighborhoods which it is eligible to join, it always chooses the one with the highest per capita investment in children.

This model will be complete once we determine the distribution of families by neighborhood. We now consider the implications of different assumptions on neighborhood structure for the dynamics of income inequality.

\section{Equilibrium with family-specific feedback effects}

In this section, we outline a model of private human capital formation. Our model is essentially equivalent to Loury [1981]. The model explores the dynamics of income when there are no cross family effects.

Assumption 1. Iurnan capital formation is a private good

Each family is a member of a separate neighborhood.

Assumption 2. Distribution of productivity shocks is a function of family-specific effects

A. The conditional probability of each productivity shock is family-specific, 


$$
\operatorname{Prob}\left(\zeta_{i, t+1} \mid \widetilde{f}_{t}\right)=\operatorname{Prob}\left(\zeta_{i, t+1} \mid Y_{i, t}\right)^{7}
$$

B. The innovation in each productivity shock is family-specific,

$$
\zeta_{i, t+1}-\mathrm{E}\left(\zeta_{i, t+1} \mid \mathfrak{F}_{t}\right) \text { is independent of } \zeta_{i^{\prime}, t+1}-\mathrm{E}\left(\zeta_{i^{\prime}, t+1} \mid \mathfrak{F}_{t}\right)
$$

Given these assumptions, it is straightforward to verify that there exist equilibrium human capital and consumption sequences for each family in this economy.

Theorem 1. Existence and probability structure of equilibrium in economy with familyspecific feedback effects

A. For each family $i$, there exists a sequence of consumption and human capital choices such that each generation maximizes expected utility subject to the aggregate production function.

B. Each family's income obeys a conditional probability structure of the form

$$
\operatorname{Prob}\left(Y_{i, t+1} \mid \mathfrak{F}_{t}\right)=\operatorname{Prob}\left(Y_{i, t+1} \mid Y_{i, t}\right)
$$

The behavior of relative income in this model will depend on the properties of the Markov chain which characterizes the evolution of family income. In particular, the following theorem illustrates how permanent inequality will emerge from identical initial conditions only if there are income states from which a family can never escape.

Theorem 2. Conditions for presence of permanent income inequality

\footnotetext{
${ }^{7}$ Throughout, $\operatorname{Prob}(x \mid y)$ denotes the conditional probability of $x$ given $y$.
} 
For the process characterizing individual family income, if $\bar{Y}_{m}$ communicates ${ }^{8}$ with $\bar{Y}_{m+n}$ for all $m, n>0$, then either income inequality is not permanent, i.e.

$$
\operatorname{Prob}\left(Y_{i, t+s}-Y_{j, t+s}>0 \forall s>0 \mid Y_{i, t}-Y_{j, t}>0\right)=0
$$

or for all $r>0$

$$
\text { The set }\left\{\bar{Y}_{1}, \ldots \bar{Y}_{r}\right\} \text { is transient. }{ }^{9}
$$

The conditions of the theorem permit one family to always have greater income than another, but only if both family incomes are becoming infinite with probability 1. Permanent poverty will therefore be a feature of permanent inequality only if there are low income absorbing states for the Markov process describing family income. Intuitively, poverty requires that some families get stuck within a certain income range which other families can avoid. The combination of poverty and inequality thus requires that the stochastic process governing family income is nonergodic.

In this model, low income absorbing states naturally correspond to income levels where liquidity constraints are binding. When agents are too poor, they cannot form sufficient human capital in their offspring to allow them to attain high income occupations. These absorbing states correspond to a stochastic generalization of the multiple equilibria derived by Galor and Zeira [1989].

\footnotetext{
${ }^{8}$ When we say that element $\bar{Y}_{m}$ communicates with element $\bar{Y}_{m^{\prime}}$ of the state
} space for family income, we mean that there is positive probability that a family with income $\bar{Y}_{m}$ attains $\bar{Y}_{m^{\prime}}$ in the future.

${ }^{9}$ If a set of states is transient, then the stochastic process under analysis will, with probability one, never re-enter these states after some finite length of time. 


\section{Equilibrium with economy-wide feedback effects}

We next consider the evolution of the economy when all families occupy a common neighborhood. The equilibrium in this economy corresponds to the public education model studied by Glomm and Ravikumar [1990]. The key feature of this model is that all children experience the same intertemporal feedback effects.

Assumption 3. Human capital formation is an economy-wide good

All families are members of the same neighborhood.

$$
\text { For all families } i, i \in \mathfrak{N}_{0, t} \text {. }
$$

Assumption 4. Distribution of productivity shocks is a function of economy-wide effects

$$
\operatorname{Prob}\left(\zeta_{i, t+1} \mid \mathfrak{F}_{t}\right)=\operatorname{Prob}\left(\zeta_{i, t+1} \mid \hat{f}_{Y}\left(\mathfrak{N}_{0, t}\right)\right) \cdot{ }^{10}
$$

The existence of an equilibrium in this economy is equivalent to the existence of a sequence of equilibrium tax rates. As is well known, an equilibrium tax rate may not exist due to nontransitive voting behavior. It is easy to establish that preferences are single-peaked with respect to tax rates in this economy, which rules out nonexistence problems. To see this, consider the choice of the tax rate which agent $i, t-1$ would make if he could dictate to the entire community. Our restrictions on the utility and production functions jointly imply that individual utility must be monotonically increasing over $\tau_{0, t}$ values below an individual's most preferred tax rate and decreasing over $\tau_{0, t}$ values above that level. Therefore, there must exist at least one tax rate in

${ }^{10} \hat{f}_{Y}\left(\mathfrak{N}_{d, t}\right)$ denotes the empirical probability measure of income for families in neighborhood $\mathfrak{n}_{d, t}$. 
each period such that at least half of the population would be opposed to any change in the rate, which means that there exists at least one equilibrium tax rate. By choosing any procedure to resolve ties, the tax rates are determined. The existence of an equilibrium sequence of tax rates is equivalent to the existence of an equilibrium stochastic process for individual and aggregate income.

Theorem 3. Existence and probability structure of equilibrium with economy-wide feedback effects

A. There exists a joint stochastic process over income, consumption and human capital accumulation for all families in all periods where tax rates are determined by majority voting.

B. Each family's income obeys a conditional probability structure of the form

$$
\operatorname{Prob}\left(Y_{i, t+1} \mid \mathfrak{F}_{t}\right)=\operatorname{Prob}\left(Y_{i, t+1} \mid \hat{f}_{Y}\left(\mathfrak{\Re}_{0, t}\right), I\right) .{ }^{11}
$$

This economy cannot generate any intertemporal income inequality, unlike the economy in section 3. The difference follows immediately from the elimination of any differences in the human capital formation and productivity shock probability distributions across the young. The models in sections 3 and 4 thus represent polar cases illustrating how forces in the economy which affect the degree of cross-section income stratification can affect intertemporal income equality. Homogeneous neighborhoods allow different income classes to evolve separately from one another. Heterogeneous neighborhoods promote equality through the effects of the rich on the poor through both

\footnotetext{
${ }^{11} I$ appears in this conditional probability due to the effect of neighborhood size on per capita expenditure requirements for each human capital level, as reflected in the function $g(\cdot, \cdot)$ described in section 2 .vii.
} 
redistribution and role model effects. This difference illustrates how the public good feature of education helps to offset the incompleteness of human capital markets, as redistribution can counteract the liquidity constraints affecting the poor. The way in which neighborhoods are endogenously determined therefore becomes a key feature in understanding the dynamics of income distribution and the persistence of poverty.

5. Equilibrium with endogenous neightorhood formation and local feedback effects

We now consider an economy where families organize themselves into neighborhoods. The dynamics of this economy depend critically on the evolution of the distribution of families by neighborhood. This evolution in turn depends on the interaction of several factors. Decreasing per capita costs in the production of human capital and mobility costs will promote income heterogeneity within neighborhoods. On the other hand, the proportional tax assumption means that heterogeneity also leads to redistribution from rich to poor, creating incentives for the wealthy to form isolated communities. The rich may also choose to isolate themselves from the poor in order to induce a more favorable conditional probability distribution for their children's productivity shocks. Alternatively, concave preferences may lead a poor minority to avoid taxes set by the rest of the economy. As suggested by the results in sections 3 and 4 , inequality emerges in response to forces which act to promote the stratification of communities by income.

\section{i. Characterization of equilibrium}

First, we assume that productivity shocks across individuals are determined by a combination of neighborhood-specific and individual-specific effects. 
Assumption 5. Productivity shocks are a combination of ncighborhood-specific and family-8pecific effects

A. The conditional probability of each productivity shock is neighborhood-specific,

$$
\operatorname{Prob}\left(\zeta_{i, t+1} \mid \mathfrak{F}_{t}\right)=\operatorname{Prob}\left(\zeta_{i, t+1} \mid \hat{f}_{Y}\left(\mathfrak{N}_{d, t}\right)\right) \text { where } i \in \mathfrak{N}_{d, t} \text {. }
$$

B. The conditional distribution of the productivity shocks is monotonically shifted to the right by a monotonic shift to the right of the empirical distribution of income. If $f_{1}$ and $f_{2}$ are two realizations of $\hat{f}_{Y}\left(\mathfrak{N}_{d, t}\right)$, then

$$
\begin{gathered}
\text { If } \int_{-\infty}^{a} f_{1}(\omega) d \omega \leq \int_{-\infty}^{a} f_{2}(\omega) d \omega \forall a \text {, then } \\
\int_{-\infty}^{b} \operatorname{Prob}\left(\zeta_{i, t+1} \mid f_{1}\right) d \zeta \leq \int_{-\infty}^{b} \operatorname{Prob}\left(\zeta_{i, t+1} \mid f_{2}\right) d \zeta \forall b .
\end{gathered}
$$

C. The innovation in each productivity shock is a combination of a neighborhood-specific component $\gamma_{d, t+1}$ and a family-specific component $\gamma_{i, t+1}$,

$$
\zeta_{i, t+1}-E\left(\zeta_{i, t+1} \mid \mathfrak{F}_{t}\right)=\gamma_{d, t+1}+\gamma_{i, t+1}
$$

$\gamma_{d, t+1}$ and $\gamma_{i, t+1}$ are identically distributed over $d$ and $i$ and are independent of each other and all $\gamma_{d^{\prime}, t+1}$ and $\gamma_{i^{\prime}, t+1}$.

Part $A$. of the assumption generalizes the probability structure of the previous models to the case of multiple neighborhoods. Part B. says that higher incomes promote more favorable productivity realizations in a neighborhood. This assumption is similar to the human capital complementarities used by deBartolome [1991] and Bénabou [1991]. See Streufert [1991] for a comprehensive analysis of how a neighborhood income distribution 
can affect career choices. Notice that if this feedback effect is due to the presence of successful role models, then the addition of poor families to a wealthy neighborhood will not necessarily have any adverse effect on the wealthy. Part $C$. introduces a factor structure for the unpredictable component of productivity shocks.

Second, we define a set of rules for the formation of neighborhoods based on the assumption that communities can erect income barriers to keep poorer families from entering. This corresponds to the situation where house prices, possibly supported by zoning requirements, represent the only barrier to neighborhood entry. ${ }^{12}$ Ideally, one would like to show that by allowing neighborhoods to erect minimum income requirements for membership, there exists a configuration of families into different neighborhoods defined by income classes such that no family wishes to move to a poorer neighborhood. However, there does not necessarily exist an equilibrium with these characteristics. ${ }^{13}$ The problem is that there is no mechanism by which poor families can avoid living with rich families that is analogous to house prices. In the absence of such a barrier, the rich may move to a poor neighborhood, the poor then move out, the rich then follow, creating an unending cycle. In order to ensure that an equilibrium exists, we need to introduce some sort of cost which prevents rich families from chasing poor families from neighborhood to neighborhood. We therefore assume that families sequentially choose neighborhoods during a period but that once a family enters a neighborhood, the cost of changing neighborhoods within a period is so high that the family will not move again. ${ }^{14}$

${ }^{12}$ The use of minimum income requirements rather than housing prices supported by zoning restrictions to define neighborhood entry barriers greatly simplifies the analysis without having any qualitative effect on the results. See Durlauf [1992] for further discussion.

${ }^{13}$ Existence results derived in Westhoff [1977] require strong additional restrictions on the joint distribution of utility functions and income far beyond those we impose and are based on a much different specification of the economy. For example, Westhoff assumes that a continuum of consumers are allocated among a finite number of communities with no role for income barriers to exclude families. 
Assumption 6. Rules for ncighborhood formation

A. At the beginning of time $t$ all productivity shocks $\zeta_{i, t}$ are realized and income is determined for each family. Each agent knows the empirical distribution of income among children of families in $\mathfrak{N}_{d, t-1}$ as well as \#( $\left.\mathfrak{n}_{d, t-1}\right)$ for all neighborhoods $d$.

B. All families are ordered by income from high to low. The highest income family moves first, choosing a neighborhood and erecting an income barrier which prevents families below the barrier from entering the neighborhood. The barrier can be set at any level less than or equal to the family's income.

C. Each family then proceeds to enter a neighborhood in order of descending income. Each family either chooses a neighborhood from among those in which it meets the income requirement or enters an empty neighborhood.

D. A majority of families who have entered any neighborhood during time $t$ can change the income requirement for joining the neighborhood at any point during the process of neighborhood formation. The new barrier cannot exclude any of the families that have entered the neighborhood during time t.

E. If family $i$ changes neighborhoods between $t-1$ and $t$, agent $i, t-1$ pays a fixed mobility cost $\bar{M}$.

This sequential algorithm always produces an equilibrium neighborhood configuration. The procedure further ensures that the upper tail of the income

${ }^{14}$ Metaphorically, entering a neighborhood requires one to invest a high percentage of income into a house which cannot be resold except at a very large loss. 
distribution can always form a distinct neighborhood, permits all families to live in the same neighborhood if unanimously agreed upon, and avoids forcing the poor to live with the rich. The chief disadvantage of the procedure is that a different ordering of the families will produce different configurations, although no ordering can ever force the rich to live with the poor. Part $E$. introduces an intertemporal mobility cost (which may be interpreted as a preference for one's childhood neighborhood) which augments decreasing per capita human capital costs as a source of neighborhood heterogeneity; none of our results change when $\bar{M}=0$.

With this assumption, one can prove theorem 4 .

Theorem 4. Existence and probability structure of equilibrium in cconomy with endogenous neighborhood formation and local feedback effects

A. There exists a joint stochastic process over consumption, neighborhood membership and taxes for all families at all dates such that each agent $i, t$ is maximizing expected utility subject to the aggregate production function and constraints on neighborhood membership.

B. Each family's income obeys a conditional probability structure of the form

$$
\operatorname{Prob}\left(Y_{i, t+1} \mid \mathfrak{F}_{t}\right)=\operatorname{Prob}\left(Y_{i, t+1} \mid \hat{f}_{Y}\left(\mathfrak{N}_{d, t}\right), \#\left(\mathfrak{N}_{d, t}\right)\right)
$$

This economy exhibits complex dynamics over time. Neighborhoods emerge and disappear as families trade off incentives for heterogeneous neighborhoods versus homogeneous neighborhoods to determine the level of economic stratification. Alternative specifications of the functional forms and parameters of our model can produce extremely different cross-section and intertemporal behavior across family incomes. We now describe some sufficient conditions for the emergence of poverty, prosperity and persistent 
inequality in the economy by placing some restrictions on the behavior of families in and out of poverty.

\section{ii. The emergence of persistent poverty}

In order to understand how persistent poverty can emerge in this model, it is necessary to bound the conditional probability characterizing the occupation choices of children born in poor neighborhoods. This bound characterizes the degree of persistence in poverty, once some set of families is isolated in the low income states.

$$
\begin{gathered}
\operatorname{Prob}\left(Y_{i, t+1} \leq \bar{Y}^{\text {pov }} \forall i \in \mathfrak{N}_{d, t} \mid\right. \\
\left.\hat{f}_{Y}\left(\mathfrak{N}_{d, t}\right) \text { such that } Y_{i, t} \leq \bar{Y}^{\text {pov }} \forall i \in \mathfrak{N}_{d, t}, \#\left(\mathfrak{N}_{d, t}\right)\right)=1-\ell
\end{gathered}
$$

When $\epsilon$ is small, uniform neighborhood poverty is persistent. When $\epsilon=0$, the poverty is permanent. In terms of the underlying stochastic process characterizing family income, this means that low income levels do not communicate with high income levels.

The case where $\epsilon=0$ is the stochastic generalization of the poverty trap derived by Bénabou [1991], Galor and Zeira [1991] and others. In fact, any of the multiple equilibrium models in Cooper and John [1988] can be interpreted as producing poverty traps of the form (23). The endogenous neighborhoods model captures the main features of the previous work on poverty traps through the feedback of community income to the income of offspring. ${ }^{15}$ We therefore follow other authors and take as given that poverty is persistent in uniformly poor neighborhoods. The goal of our analysis is to see whether poor stricken communities can emerge endogenously from nonpoor initial conditions.

The existence of low income trapping states does not, in fact, mean that any families are actually trapped in poverty for substantial lengths of time. Forces which promote heterogeneous neighborhoods can prevent any families from being isolated into low income communities. Poverty emerges if (with positive probability) poor families 
become isolated from the rest of the economy, leaving them unable to accumulate human capital. We therefore make an assumption which says that the maximum income among families within a neighborhood can decrease over time, for some income range.

Assumption 7. Feasible range of income movernents

There exists an income level $\bar{Y}^{\text {thresh }}$ with $\operatorname{Prob}\left(\max _{i \in \mathfrak{J}} Y_{i, t}<\bar{Y}^{\text {thresh }}\right.$ for some $\left.t\right)>0$ such that for any neighborhood $\mathfrak{N}_{d, t}$,

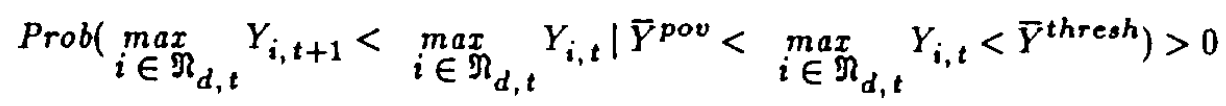

This assumption is much weaker than one which says that all families can experience downward mobility every period regardless of income or neighborhood. All we require is that the wealthiest family in each neighborhood can move downward over some income range. For any choice of the utility and production functions there will always

${ }^{15}$ To see how $\epsilon=0$ may be generated by our model, observe that (23) imposes restrictions on both the level of human capital investment and the distribution of productivity shocks in poor neighborhoods. First, human capital investment in poor children cannot allow them to leave poverty, i.e. there exists a $b$ (which may depend on the neighborhood income distribution) such that

$$
\text { For all families } i \in \mathfrak{N}_{d, t} \text { such that } Y_{i, t} \leq \bar{Y}^{\text {pov }} \forall i \in \mathfrak{N}_{d, t}, H_{i, t} \leq e_{p-b} \text {. }
$$

Given the borrowing constraints in the model, which require that all educational expenditures are financed by within-neighborhood taxes, this condition will hold, for example, when the fixed costs to operating a school district are sufficiently high or the the $u(\cdot)$ function is sufficiently concave at low consumption levels. Second, productivity shocks must be bounded from above with probability 1 ,

$$
\operatorname{Prob}\left(\zeta_{i, t+1} \leq b \forall i \in \mathfrak{N}_{d, t} \mid \hat{f}_{Y}\left(\mathfrak{N}_{d, t}\right) \text { such that } Y_{i, t} \leq \bar{Y}^{\text {pou }} \forall i \in \mathfrak{N}_{d, t}\right)=1 .
$$

This condition will hold if the effect of uniform poverty on productivity shocks is strong enough. 
exist specifications of the distribution of $\zeta_{i, \ell}$ which fulfill the assumption. Assumption 7 immediately implies theorem 5 .

Theorem 5. Persistent poverty

Under assumptions 5, 6, and 7, for any family $i$, there exists a set $A_{1} \subset \bar{Y}^{I}$ with $\operatorname{Prob}\left(\underline{Y}_{t} \in A_{1}\right.$ for some $\left.t\right)>0$ such that

A. For sufficiently small $c$ in eq. (23), the probability that the family is trapped in poverty over any finite interval $S$ can be made arbitrarily close to 1 . For any $\xi>0$,

$$
\operatorname{Prob}\left(Y_{i, t+s} \leq \bar{Y}^{\text {pov }} \forall s \in[1, \ldots, S] \mid \underline{Y}_{t} \in A_{1}\right)>1-\xi
$$

B. For $\epsilon=0$, family i becomes permanently trapped in poverty.

$$
\operatorname{Prob}\left(Y_{i, t+s} \leq \bar{Y}^{\text {pov }} \forall s>0 \mid \underline{Y}_{t} \in A_{1}\right)=1
$$

Theorem 5 does not preclude the possibility that human capital per adult is growing among all families early on. The key to our results is that as the wealthier residents isolate themselves, human capital accumulation among others slows down and can even reverse itself.

\section{iii. The emergence of prosperity}

We next consider how the economy can exhibit sample paths along which some families always avoid poverty. One possibility is that there exists an income threshold such that if neighborhood income exceeds this level, family income can never move down across time. Such an assumption would require either that negative productivity shocks 
disappear among the nonpoor or that nonpoor families invest in children at such a rate that negative shocks never cause downward mobility. The elimination of any negative shocks would appear to be unnatural to the model even if poverty were a persistent state. For example, the arguments made by Wilson [1987] in explaining the culture of poverty, which imply that positive shocks among poor children are unlikely, do not imply that wcalthy children will always be as able as their parents, given a constant level of human capital investment across generations. Further, the assumption that sufficiently wealthy families will invest so much human capital in their children that downward mobility is eliminated implies a very strong restriction on preferences. A more natural approach may be based on the idea that nonpoor families partially insure their children against negative shocks by choosing an increasing sequence of human capital investments over time. In this case, the average income of a nonpoor family grows across time.

In fact, growth can allow permanent prosperity to occur even if all income states communicate with all lower income states. In a growing economy, nonpoor families will, on average, move away from the low income states. An upward drift in income attenuates the probability of a family ever becoming poor by rendering the sequence of shocks necessary to drive a family into poverty less and less likely. This idea is captured in assumption $8 .^{16}$

\section{Assumption 8. Conditions for evolution of family occupations outside of poverty}

All families located in neighborhoods without poverty experience positive expected growth in occupation level. There exists a $\nu>0$ such that for all $i \in \mathfrak{N}_{d, t}$,

$$
\mathrm{E}\left(Y_{i, t+1}-Y_{i, t} \mid \hat{f}_{Y}\left(\mathfrak{N}_{d, t}\right) \text { such that } Y_{i, t}>\bar{Y}^{\text {pov }} \forall i \in \mathfrak{N}_{d, t}, \#\left(\mathfrak{N}_{d, t}\right)\right) \geq \nu
$$

${ }^{16}$ See Jones and Manuelli [1990] for a general analysis of how growth can emerge in models similar to ours. 
Assumption 8 is sufficient to prove that some families can escape poverty.

\section{Theorem 6. Permancnt prosperity}

Under assumptions 5, 6, 7, and 8, the probability that a family permanently escapes poverty is positive. For any family $i$, there exists a set $A_{2} \subset \bar{Y}^{I}$ with Prob $\left({\underset{\sim}{t}}_{t} \in A_{2}\right.$ for some $t)>0$ such that

$$
\operatorname{Prob}\left(Y_{i, t+s}>\bar{Y}^{\text {pov }} \forall s>0 \mid Y_{t} \in A_{2}\right)>0
$$

\section{iv. The emergence of persistent inequality}

Theorems 5 and 6 provide general conditions for income extremes to emerge over the history of an economy. In order for inequality to emerge, it is necessary not only that each family can achieve poverty or prosperity over a sample path realization of the economy, but that different families can achieve distinct outcomes. Since families within a neighborhood experience common intertemporal influences which eliminate expected intertemporal income differences, persistent inequality requires that families segregate themselves by income over time. Specifically, distinct neighborhoods must emerge over time which are preserved under increasing income inequality. We therefore make a very strong assumption on the dynamics of neighborhood formation. The assumption is clearly sufficient rather than necessary, but illustrates an intuitive set of conditions.

\section{Assumption 9. Endogenous stratification}

There exists a pair of values $\bar{Y}^{\text {high }}$ and $\bar{Y}^{\text {low }}$, with $\bar{Y}^{\text {high }}>\bar{Y}^{\text {low }}, \bar{Y}^{\text {high }}>\bar{Y}^{\text {pov }}$ and $\bar{Y}^{\text {low }}<\bar{Y}^{\text {thresh }}$, such that ${ }^{17}$

\footnotetext{
${ }^{17}$ See assumption 7 for the definition of $\bar{Y}^{\text {thresh }}$.
} 
A. With positive probability all families across all neighborhoods either have incomes $Y_{i, t} \geq \bar{Y}^{\text {high }}$ or incomes $Y_{i, t} \leq \bar{Y}^{\text {low }}$ for some $t$.

B. Given any income configuration such that all families either have incomes $Y_{i, t} \geq \bar{Y}^{\text {high }}$ or incomes $Y_{i, t} \leq \bar{Y}^{\text {low }}$, no neighborhood will form which contains both a family with income $Y_{i, t} \geq \bar{Y}^{\text {high }}$ and a family with income $Y_{i, t} \leq \bar{Y}^{\text {low }}$.

This assumption ensures that with positive probability, the economy will stratify itself into income groups which are preserved as inequality, as measured by the gap between the groups, increases. Assumptions 7, 8, and 9 produce an economy that is capable of experiencing large income disparities which are preserved across time. This feature is summarized in theorem 7 .

Theorem 7. Persistent income inequality

Under assumptions 5, 6, 7, 8, and 9, for any families $i$ and $j$, there exists a set $A_{3} \subset \bar{Y}^{I}$ with Prob $\left(Y_{t} \in A_{3}\right.$ for some $\left.t\right)>0$ such that

A. For sufficiently small $\epsilon$ in eq. (23), inequality between the families persists over any finite time interval $S$ with probability arbitrarily close to 1 . For any $\xi>0$,

$$
\operatorname{Prob}\left(Y_{i, t+s}>\bar{Y}^{p o v} \geq Y_{j, t+s} \forall s \in[1, \ldots, S] \mid Y_{-t} \in A_{3}\right)>1-\xi
$$

B. For $\epsilon=0$, inequality is permanent with probability arbitrarily close to 1 . For any $\xi>0$,

$$
\operatorname{Prob}\left(Y_{i, t+s}>\bar{Y}^{\text {pov }} \geq Y_{j, t+s} \forall s>0 \mid{\underset{\sim}{Y}}_{t} \in A_{3}\right)>1-\xi
$$


We note seven features of the equilibrium with poverty. First, the equilibrium is inefficient, in the sense that the marginal productivity of human capital investment is not equal across agents. This holds both because the output increase associated with a rise in the occupation of a poor agent is greater than that of a wealthy agent as well as because wealthy agents do not account for the feedback effects on the distribution of productivity shocks the rich can induce by letting poor agents into the community.

Second, forcing all families to live in the same community will not always lead to an increase in per capita output, although it of course eliminates intertemporal inequality. If the resources of society are scarce enough, the imposition of income redistribution through equal education may prevent any families from achieving sustained growth in income. Inequality might very well be a prerequisite to growth in the economy as a whole. This is most likely to occur when there are relatively many poor agents.

Third, there also exist versions of these models where poverty is less likely to occur in the single neighborhood economy than the endogenous neighborhood economy. For example, if the empirical measure of productivity shocks across all agents is symmetric with zero mean, then the single neighborhood economy can behave in a fashion similar to an economy with no individual shocks. Such an economy can easily exhibit growth. When endogenous neighborhood formation is allowed, then poorer families can drift off to the low income absorbing states. Heterogeneous neighborhoods thus can act as a sort of insurance against family income fluctuations. Endogenous stratification can itself become a source of multiple long run equilibria emerging across individual families in the economy. Notice that if we modify the model to allow for negative correlations in productivity shocks across neighborhoods, these insurance effects are particularly likely to be important.

Fourth, income transfers to the poor may be cost-ineffective as a means of raising income in some communities. If the neighborhood-specific productivity effects are too strong, greater human capital investment may have little impact on the income of the 
poor. Put differently, strong productivity effects may require very large human capital expenditures to move communities out of poverty.

Fifth, the model can be modified to eliminate the feature that the income gap between rich and poor must become unbounded. Specifically, the difference between $\bar{Y}_{k+1}-\bar{Y}_{k}$ can be decreasing in $k$. In this case, assumption 8 must be replaced by a condition that for all nonpoor neighborhoods there exists a $\nu$ such that

$$
\mathrm{E}\left(\theta_{i, t+1}-\theta_{i, t} \mid \hat{f}_{Y}\left(\mathfrak{N}_{d, t}\right) \text { such that } Y_{i, t}>\bar{Y}^{\text {pov }} \forall i \in \mathfrak{N}_{d, t}, \#\left(\mathfrak{N}_{d, t}\right)\right) \geq \nu
$$

so that growth in occupational status is preserved for the nonpoor. This alternative formulation still implies that the income distribution may be bimodal for a fixed population size.

Sixth, by introducing population growth, one can produce equilibria exhibiting persistent inequality without requiring that all families are concentrated at the two ends of the income range. The disappearance of intermediate occupations which occurs in the model as rich and poor families separate is an artifact of the assumption that the number of families is fixed. If new families enter the economy over time, then intermediate occupations and income levels will never disappear.

Seventh, the private human capital formation economy of section 3 is a special case of the endogenous neighborhoods model. When mobility costs and the effects of increased neighborhood size on required per capita expenditure for a fixed human capital level are small enough, there is no incentive for any family to share a community with a poorer family, which means each family must occupy a distinct neighborhood. Consequently, the model in section 3 can emerge from a variant of the specification in this section. The general endogenous neighborhoods model, however, generates far richer dynamics than the private education special case. Unlike the private education model, the general endogenous neighborhoods model predicts that the persistence of poverty will differ according to whether a family is or is not located in a uniformly poor 
neighborhood. This distinction is emphasized by Wilson [1987] in the sociology literature and is an implication of empirical work such as Datcher [1982] and Corcoran, Gordon, Laren and Solon [1989]. In addition, the endogenous neighborhoods model can be used to study phenomena such as the breakup of heterogeneous urban communities, which is the subject of the next section.

\section{Urban/suburban interactions}

In this section, we examine a variant of the endogenous neighborhoods model to see how income inequality can emerge in the context of the breakup of urban communities. Much of the literature on the underclass (see Wilson [1987]) has emphasized that the underclass is composed of the residual members of large inner city communities where the wealthier members have departed for suburbs. Further, a number of authors have argued that the historical experience of many American cities is well described as a discontinuous withdrawal of wealthy whites from urban centers in response to changes in the economic and racial composition of neighborhoods, a phenomenon known as tipping. (See Schelling [1971] for a discussion and references.) These features can be modelled through the decision of families to leave a heterogeneous neighborhood in favor of homogeneous communities, which we interpret as suburbs.

Our analysis builds directly on the model in Section 5; see Durlauf [1992] for a more general version of urban/suburban dynamics. Assumption 10 introduces the urban center which acts as the original neighborhood for all families. The urban center augments the endogenous neighborhoods model as it is open to all families regardless of income. Assumption 11 describes a fixed cost in the human capital production function, which acts with the mobility cost $\bar{M}$ in Assumption 6 to help preserve the urban center.

Assumption 10. Properties of urban center 
A. All families are members of neighborhood $\mathfrak{\Omega}_{0,0}$.

B. Neighborhoods are formed according to the rules of assumption 6 . However, no family may be excluded from neighborhood $\mathfrak{N}_{0, t}$ through an income barrier.

Assumption 11. Fixed cost in human capital production function

Human capital production contains a fixed cost $\bar{F}$,

$$
g\left(H_{i, t}, \#\left(\mathfrak{N}_{d, t}\right)\right)=\frac{\bar{F}}{\#\left(\mathfrak{R}_{d, t}\right)}+f\left(H_{i, t}, \#\left(\mathfrak{N}_{d, t}\right)\right)
$$

where

$$
\frac{\partial f\left(H_{i, t}, \#\left(\mathfrak{N}_{d, t}\right)\right)}{\partial \#\left(\mathfrak{N}_{d, t}\right)} \geq 0 .
$$

When redistribution from rich to poor in the urban center is large enough, wealthy agents have an incentive to abandon the community and form their own neighborhoods. If the tax base of the initially heterogeneous neighborhood deteriorates sufficiently, the urban center can become a poverty trap. The emergence of this residual poor neighborhood will depend on the sample path realization of the income distribution; some realizations can cause discontinuous changes in the composition of $\mathfrak{R}_{0, t}$. Theorem 8 illustrates how endogenous stratification and the breaking up of the urban center are functions of the realized income distribution.

Theorem 8. Properties of urban/suburban communitics model ${ }^{18}$ 
Suppose that all families $i, t-1$ inhabit $\mathfrak{N}_{0, t-1}$. Given assumptions $5,6,7,8,10$, and 11 , there exists a set $A_{4} \subset \bar{Y}^{I}$ such that

A. If $\underline{Y}_{\mathbf{t}} \in A_{\mathbf{4}}$, then the urban center will break up at $t$.

B. If $\operatorname{Prob}\left(\underline{Y}_{t} \in A_{4}\right)>0$, then theorems 5, 6, and 7 all hold.

Theorem 8 does not rely on the percentage of poor in a neighborhood to drive the wealthy out as do most tipping models. However, whenever incomes differences are large enough, changes in the percentage of poor will affect the preservation of the neighborhood. See Durlauf [1992] for a general analysis.

\section{Summary and conclusions}

This paper describes the evolution of the distribution of income and the possible emergence of poverty in an economy where families determine the level of education as a local public good. In our model, wealthy families have an incentive to isolate themselves from the rest of the economy in order to provide the highest level of education of their children at the lowest cost. Decreasing average costs in human capital formation function and mobility costs, on the other hand, create incentives for communities to emerge with heterogeneity in income across agents. When the forces leading to homogeneity are strong enough, endogenous stratification of the economy can occur, causing poor families to be isolated from the rest of the population. This isolation can induce persistent or permanent poverty among some families as they are unable to jointly generate sufficient human capital investment in their children to escape from low paying occupations. The

\footnotetext{
${ }^{18}$ We relax assumption 9 in order to show how endogenous stratification arises directly from the production and preference structure that has been specified.
} 
model exhibits nonergodic dynamics as different sample path realizations of the same microeconomic structure can produce different levels of aggregate wealth. Nonergodicity holds at an individual level as families with identical initial conditions and preferences can converge to different long run levels of income.

Methodologically, the paper illustrates how endogenous stratification can lead identically specified agents to converge to different equilibria within the same economy. The idea that high production agents are more likely to interact with other successful agents is powerful as it represents a mechanism for understanding how multiple long run equilibria can emerge as the outcome of a dynamic process. Endogenous stratification models thus can allow the incomplete markets/coordination failure literature to address cross-section/time series questions.

In terms of future research, endogenous stratification can lead to persistent income inequality through a number of other mechanisms. One possibility is to explore the role of successful firms in income distribution. In a world of increasing returns technologies, if high output firms are more likely to trade with other high output firms, then multiple trading networks will develop. Average output can vary across the networks. In this case, the multiple equilibria described in Murphy, Shleifer and Vishny [1989] can coexist across firms and industries within the same economy.

In addition, there are a number of interesting extensions of the current paper. One important issue centers on how a society should structure income redistribution in order to maximize expected utility over time. ${ }^{19}$ One can think of redistribution schemes which act to complete the missing markets whose effects manifest themselves through rising inequality. Second, if the productivity of each occupation is an increasing function of the education level of the society, then redistribution incentives will exist for the rich as the economy evolves. Both of these channels would provide a means of developing a positive theory of income redistribution by the government.

\footnotetext{
${ }^{19}$ See Cooper [1992] for the development of a positive theory of redistribution.
} 


\section{Bibliography}

Adams, Terry, Greg Duncan and Willard Rogers, "The Persistence of Poverty," in Quiet Riots: Race and Poverty in the United States, Fred R. Harris and Roger W. Wilkins (eds.), New York: Pantheon Books, 1988.

Aghion, Philippe and Patrick Bolton, "A Trickle-Down Theory of Growth and Development with Debt-Overhang," Working Paper, DELTA, Paris, 1991.

Bane, Mary Jo and David T. Ellwood, "Slipping Into and Out of Poverty: The Dynamics of Spells," Journal of Human Resources, 21, 1-23, 1986.

Banerjee, Abhijit and Andrew F. Newman, "Risk-Bearing and the Theory of Income Distribution," Review of Economic Studies, 58, 211-235, 1991.

Becker, Gary S. and Nigel Tomes, "An Equilibrium Theory of the Distribution of Income and Intergenerational Mobility," Journal of Political Economy, 87, 1153-1189, 1979.

Bénabou, Roland, "Workings of a City: Location, Education, and Production," Working Paper, MIT, 1991.

Brittain, John A., The Inheritance of Economic Status, Washington D. C.: Brookings Institution, 1977.

Card, David and Alan Krueger, "Does School Quality Matter? Returns to Education and the Characteristics of Public Schools in the United States," NBER Working Paper no. $3358,1990$.

Çinlar, Erhan, Introduction to Stochastic Processes. New York: Prentice Hall, 1975.

Cooper, Russell and Andrew John, "Coordinating Coordination Failures in Keynesian Models," Quarterly Journal of Economics, CIII, 441-464, 1988.

Cooper, Suzanne J., "A Positive Theory of Income Redistribution," Working Paper, Stanford University, in progress, 1992.

Corcoran, Mary, Roger Gordon, Deborah Laren and Gary Solon, "Effects of Family and Community Background on Men's Economic Status," NBER Working Paper no. 2896, 1989.

Datcher, Linda, "Effects of Community and Family Background on Achievement," 
Review of Economics and Statistics, 64, 32-41, 1982.

deBartolome, Charles, A. M., "Equilibrium and Inefficiency in a Community Model with Peer Group Effects," Journal of Political Economy, 98, 110-133, 1991.

Durlauf, Steven N., “Nonergodic Economic Growth," NBER Working Paper no. 3719, 1991.

Durlauf, Steven N. "The Dynamics of Ghetto Formation," Working Paper, Stanford University, in progress, 1992.

Fudenberg, Drew and Jean Tirole, Game Theory, Cambridge: MIT Press, 1991.

Galor, Oded and Joseph Zeira, "Income Distribution and Macroeconomics," Working Paper, Brown University, 1989.

Glomm, Gerhard and B. Ravikumar, "Public vs. Private Investment in Human Capital: Endogenous Growth and Income Inequality," Working Paper, University of Virginia, 1990.

Jaynes, Gerald D. and Robin L. Williams, ed., A Common Destiny: Blacks and American Society, Washington D.C.: National Academy Press, 1989.

Johnson, George and Frank Stafford, "Social Returns to Quantity and Quality of Schooling," Journal of Iluman Resources, 8, 139-155, 1973.

Jones, Larry and Rodolfo E. Manuelli, "A Convex Model of Equilibrium Growth," Journal of Political Economy, 98, 1008-1038, 1990.

Kozol, Jonathan, Savage Incqualitics, New York: Crown Publishers, 1991.

Loury, Glenn C., "Intergenerational Transfers and the Distribution of Earnings," Econometrica, 49, 843-867, 1981.

Murphy, Kevin, Andrei Shleifer, and Robert Vishny, "Industrialization and the Big Push," Journal of Political Economy, 97, 1003-1026, 1989.

Roberts, Kevin W. S., "Voting Over Income Tax Schedules," Journal of Public Economics, 8, 329-340, 1977.

Solon, Gary, "Intergenerational Income Mobility in the United States," Working Paper, University of Michigan, 1990. 
Schelling, Thomas, "Dynamic Models of Segregation," Journal of Mathematical Sociology, 143-186, 1971.

Stout, William F., Almost Sure Convergence, New York: Academic Press, 1974.

Streufert, Peter A., "The Effect of Underclass Isolation on Schooling Choice," Working Paper, University of Wisconsin, Madison, 1991.

Wachtel, Paul, "The Effect on Earnings of School and College Investment Expenditures," Review of Economics and Statistics, 58, 326-331, 1976.

Westhoff, Frank, "Existence of Equilibria in Economies with a Local Public Good," Journal of Economic Theory, 14, 84-112, 1977.

Wilson, William Julius, The Truly Disadvantaged, Chicago: University of Chicago Press, 1987. 